\title{
Specialized thoracic aortic team is the next step in improving outcome in acute aortic dissection care
}

\author{
Ming-Hao Guo ${ }^{1}$, Linda Y. N. Fei ${ }^{2}$, Munir Boodhwani ${ }^{1}$ \\ ${ }^{1}$ Division of Cardiac Surgery, University of Ottawa Heart Institute, Ottawa, ON, Canada; ${ }^{2}$ Faculty of Medicine, University of Ottawa, Ottawa, ON, \\ Canada \\ Correspondence to: Munir Boodhwani, MD, MSc, FRCSC. University of Ottawa Heart Institute, 340-40 Ruskin Street, Ottawa, ON K1Y 4W7, \\ Canada. Email: mboodhwani@ottawaheart.ca. \\ Comment on: Umana-Pizano JB, Nissen AP, Sandhu HK, et al. Acute Type A Dissection Repair by High-Volume Vs Low-Volume Surgeons at a \\ High-Volume Aortic Center. Ann Thorac Surg 2019;108:1330-6.
}

Submitted Feb 20, 2020. Accepted for publication Apr 24, 2020.

doi: 10.21037/jtd-2020-24

View this article at: http://dx.doi.org/10.21037/jtd-2020-24

In this issue of $\mathcal{F T D}$, Umana-Pizano et al. examined 580 acute type A aortic dissection (ATAAD) cases from 1999 to 2016 at a high-volume centre, and found that there was a 3.72-fold increase in in-hospital mortality by an all lowvolume aortic surgeon (LVAS) team compared to teams with a high-volume aortic surgeon (HVAS), and this increase in mortality extends into 5 -year of follow-up (1). HVAS was defined as $>10$ cases per year, and LVAS was defined as $\leq 10$ cases per year. The study was performed at a high-volume centre where there was no difference in resource allocation to the various team structures examined. The author concluded that the instead of hospital volume, a surgeon's case-volume may also be an important factor that influences short- and long-term outcome of ATAAD patients.

Over the past decade, the surgical mortality of ATAAD decreased significantly from $25 \%$ to $18 \%$ (2). This improvement in outcome is mainly related to better diagnostic imaging, advances in hypothermic circulatory arrests and cerebral perfusion strategies, increased safety and efficacy of aortic replacement procedures, and perioperative intensive care. However, with an in-hospital mortality of 1 in 5 patients, acute aortic dissection remains a life-threatening condition that is challenging to diagnose and treat.

To further improve surgical outcome in patients with type A aortic dissection, centre volume and surgeon case volume have been evaluated. The positive correlation between increased volume of cases and improved surgical outcome for high-risk procedures is well-studied in the literature, and underlies the process of specialization and centralization of complex surgical care $(3,4)$. In cardiac surgery, the volume-outcome relationship has been demonstrated with coronary artery bypass grafting, mitral valve surgery for mitral regurgitation, as well as aortic valve replacement (5-7). In ATAAD, multiple studies have shown that centre volume is one of the strongest predictors of perioperative outcome, and this association remains significant after adjusting for patient factors and co-morbidities $(8,9)$. In a survey of 5,184 patients from the national inpatient sample database from 2003 to 2008, Chikwe et al. found that a strong inverse relationship between operative mortality and both institution and surgeon volume. Surgeons who performed less than 1 aortic dissection repair per year had a mean operative mortality of $27.5 \%$, compared with $17.0 \%$ for those averaging 5 or more annually (10). This was similar to the relationship seen between institution volume and mortality: operative mortality was $27.4 \%$ in institutions performing 3 or fewer acute aortic dissections a year, compared with $16.4 \%$ in those performing more than 13 annually.

In practice, regionalization and the utilization of an aortic dissection pathway to a specialized multi-disciplinary aortic dissection team have also been shown to greatly improve post-operative outcome. Recently, a study of 16,886 Medicare beneficiaries looked at whether regionalizing care at high-volume hospitals for ATAADs was associated with lower mortality (11). The authors demonstrated that despite delaying surgery, a regionalization policy that transfers 
patients to high-volume hospitals was associated with a $7.2 \%$ absolute risk reduction in operative mortality, and the association persisted in the long term, with a hazard ratio of 0.81 (95\% CI, 0.75-0.87). Furthermore, Andersen et al. demonstrated that treatment of type A aortic dissection with dedicated multi-disciplinary thoracic aortic team significantly improved peri-operative outcome9.

A few questions remain to be explored. The number of cases that is required to improve patient outcome may need further delineation; as the author acknowledged, the mean experience in this study for HVAS was 15 cases/year, which may be significantly higher than most other specialized cardiac surgery centers. Whether specialized fellowship training in aortic surgery or high volume of elective aortic surgery improves outcome in ATAAD management is yet to be determined. One interesting observation from the study is that the outcome is comparable as long as there is a HVAS on the team, regardless if the HVAS was the primary surgeon or assistant. This has important implications in resident/fellow training, in that it would be justifiable for surgeon-in-training to take up the primary operator role under the guidance of the HVAS, without compromising outcome in these high-risk patients. Lastly, extrapolating on experiences in acute aortic dissection, the need for dedicated thoracic aortic team for complex elective aortic surgery involving prolonged hypothermic circulatory arrest, multiple arch vessel reconstruction, and descending thoracic aortic intervention, also needs to be further studied.

As more studies establish links between volume and outcome in specialized cardiac surgical cases, the broader notion of what constitutes adequate training and experience for a general cardiac surgeon will continue to be challenged. The next generation of cardiac surgeons will need to rise to this challenge to deliver safe, effective, and innovative care to our patients. A strong mentorship between senior surgeons and junior staff as well as senior residents or fellows are critical. For centers with dedicated aortic dissection call team, it is important to involve senior trainees in pre-operative planning as well as participation/assistance in the surgery. In centers without a dedicated dissection team, senior surgeons or surgeons with specialized aortic training should be available to provide assistance to junior surgeons. As outlined in the study, the experienced HVAS does not necessarily require to be the primary surgeon to achieve satisfactory outcome, as long as they are present to provide guidance in key elements of the surgery. In addition, a strong quality improvement program is required to review individual cases at rounds, which would provide a learning experience for surgeons and trainees that were not directly involved.

\section{Acknowledgments}

Funding: None.

\section{Footnote}

Provenance and Peer Review: This is an invited article commissioned and reviewed by the Section Editor Dr. JianCang Zhou (Department of Critical Care Medicine, Sir Run Run Shaw Hospital, Zhejiang University School of Medicine, Hangzhou, China).

Conflicts of Interest: All authors have completed the ICMJE uniform disclosure form (available at http://dx.doi. org/10.21037/jtd-2020-24). The authors have no conflicts of interest to declare.

Ethical Statement: The authors are accountable for all aspects of the work in ensuring that questions related to the accuracy or integrity of any part of the work are appropriately investigated and resolved.

Open Access Statement: This is an Open Access article distributed in accordance with the Creative Commons Attribution-NonCommercial-NoDerivs 4.0 International License (CC BY-NC-ND 4.0), which permits the noncommercial replication and distribution of the article with the strict proviso that no changes or edits are made and the original work is properly cited (including links to both the formal publication through the relevant DOI and the license). See: https://creativecommons.org/licenses/by-nc-nd/4.0/.

\section{References}

1. Umana-Pizano JB, Nissen AP, Sandhu HK, et al. Acute Type A Dissection Repair by High-Volume Vs LowVolume Surgeons at a High-Volume Aortic Center. Ann Thorac Surg 2019;108:1330-6.

2. Pape LA, Awais M, Woznicki EM, et al. Presentation, Diagnosis, and Outcomes of Acute Aortic Dissection: 17Year Trends From the International Registry of Acute Aortic Dissection. J Am Coll Cardiol 2015;66:350-8.

3. Birkmeyer JD, Siewers AE, Finlayson EV, et al. Hospital volume and surgical mortality in the United States. N Engl J Med 2002;346:1128-37. 
4. Finks JF, Osborne NH, Birkmeyer JD. Trends in hospital volume and operative mortality for high-risk surgery. $\mathrm{N}$ Engl J Med 2011;364:2128-37.

5. Hannan EL, Wu C, Ryan TJ, et al. Do hospitals and surgeons with higher coronary artery bypass graft surgery volumes still have lower risk-adjusted mortality rates? Circulation 2003;108:795-801.

6. Gammie JS, O'Brien SM, Griffith BP, et al. Influence of hospital procedural volume on care process and mortality for patients undergoing elective surgery for mitral regurgitation. Circulation 2007;115:881-7.

7. Dewey TM, Herbert MA, Ryan WH, et al. Influence of surgeon volume on outcomes with aortic valve replacement. Ann Thorac Surg 2012;93:1107-12; discussion 1112-3.

8. Knipp BS, Deeb GM, Prager RL, et al. A contemporary

Cite this article as: Guo MH, Fei LYN, Boodhwani M. Specialized thoracic aortic team is the next step in improving outcome in acute aortic dissection care. J Thorac Dis 2020;12(10):6112-6114. doi: 10.21037/jtd-2020-24 analysis of outcomes for operative repair of type A aortic dissection in the United States. Surgery 2007;142:524-8; discussion 528.e1.

9. Andersen ND, Ganapathi AM, Hanna JM, et al. Outcomes of acute type a dissection repair before and after implementation of a multidisciplinary thoracic aortic surgery program. J Am Coll Cardiol 2014;63:1796-803 .

10. Chikwe J, Cavallaro P, Itagaki S, et al. National outcomes in acute aortic dissection: influence of surgeon and institutional volume on operative mortality. Ann Thorac Surg 2013;95:1563-9.

11. Goldstone AB, Chiu P, Baiocchi M, et al. Interfacility Transfer of Medicare Beneficiaries With Acute Type A Aortic Dissection and Regionalization of Care in the United States. Circulation 2019;140:1239-50. 